\title{
Evidências de validade de critério para testes de atenção na avaliação psicológica no contexto do trânsito
}

\author{
Fabián Javier Marín Rueda ${ }^{1}$ \\ Universidade São Francisco, Campinas-SP, Brasil
}

\section{RESUMO}

A pesquisa teve como objetivo buscar evidências de validade com base em critério externo para testes que avaliam atenção e que são comumente empregados na avaliação psicológica no contexto do trânsito. Participaram 300 indivíduos do estado do Paraná que responderam aos instrumentos no momento da obtenção da Carteira Nacional de Habilitação (CNH), em 2010. Após quatro anos, em 2014, foi obtido junto ao Departamento de Trânsito do Paraná (DETRAN-PR) o histórico de infrações desses motoristas. Os resultados não mostraram diferenças significativas nas pontuações dos testes entre os grupos de motoristas com e sem registro de infração. Também não foram observadas correlações significativas entre o desempenho nos testes e o número de infrações e pontos na CNH. Discute-se a necessidade de mais pesquisas na área, que considerem outras variáveis relacionadas ao contexto do trânsito, como o envolvimento em acidentes com e sem vítimas fatais, relacionando o resultado das provas teórica e prática com o desempenho na avaliação, entre outros.

Palavras-chave: psicologia do trânsito; atenção; avaliação psicológica; validade de critério; testes psicológicos.

ABSTRACT - Evidence for Criterion validity of attention tests for psychological assessment in the traffic context The aim of the research was to obtain validity evidence based on external criteria for tests that evaluate attention and which are commonly used in the assessment of motor vehicle drivers. Participants were 300 individuals from the State of Paraná who answered to the instruments at the time of obtaining their driver's licenses (CNH), in 2010. After four years, in 2014, the history of infractions of these drivers was obtained from the department of traffic of Paraná (DETRAN-PR). The results did not show significant differences in test scores comparing the group of drivers with infraction records and those without infraction records. There were also no significant correlation between the performance in the tests and the number of infractions and points in the CNH. Further studies are necessary in the field, considering other variables involved in the context of traffic, such as involvement in accidents with and without fatalities, relating the results of the theoretical and practical tests with the performance in the evaluation, among others.

Keywords: traffic psychology; attention; psychological assessment; criterion validity; psychological testing.

RESUMEN - Evidencias de validez de criterio para pruebas de atención en la evaluación psicológica en el contexto del tránsito

La investigación tuvo como objetivo buscar evidencias de validez con base en criterio externo para pruebas que evalúan la atención y que son bastante utilizadas en la evaluación psicológica en el contexto del tránsito. Participaron 300 individuos del estado de Paraná que respondieron los instrumentos en el momento de la obtención de la cartera nacional de habilitación (CNH), el año 2010. Después de cuatro años, en 2014, se obtuvo el histórico de infracciones de esos conductores junto al Departamento de Tránsito de Paraná (DETRAN-PR). Los resultados no mostraron diferencias significativas en las puntuaciones de las pruebas entre los grupos de conductores con y sin infracciones. Tampoco se observaron correlaciones significativas entre el desempeño en las pruebas y el número de infracciones y de puntos en la CNH. Se discute la necesidad de más investigaciones en el área que tomen en consideración otras variables relacionadas al contexto del tránsito, como saber si la persona se involucró en accidentes con o sin víctimas fatales, relacionando el resultado de las pruebas teórica y práctica con el desempeño en la evaluación, entre otros.

Palabras clave: psicología del tránsito; atención; evaluación psicológica; validez de criterio; tests psicológicos.

A Psicologia do Trânsito é uma área ampla de estudo que abarca não apenas os motoristas, mas todos os envolvidos no sistema trânsito (Rozestraten, 1988). No entanto, em 1978, Shinhar já destacava que ela era uma área centrada apenas no motorista e nas características psicológicas que poderiam influenciar o desempenho no ato de dirigir. Nesse sentido, Rueda (2011) destaca que, embora a Psicologia do Trânsito possa e deva 
ser considerada como um campo amplo de atuação, no Brasil, desde seu surgimento, ela vem sendo utilizada como sinônimo de avaliação psicológica de motoristas.

Do ponto de vista legal, seu surgimento pode ser estabelecido a partir da década de 1950, época na qual já se destacavam os construtos avaliados e, entre eles, citava-se a atenção (Vieira, Pereira, \& Carvalho, 1953). Tais autores também destacavam que não existia um perfil definido que indicasse o que deveria ser considerado para determinar se a pessoa estava apta ou não para dirigir. No entanto, e em que pese essa falta de definição sobre o que avaliar, em 1962, o Conselho Nacional de Trânsito (CONTRAN) estendeu a avaliação a todos os candidatos à obtenção da Carteira Nacional de Habilitação (CNH). A partir dessa data, o processo passou a ser muito semelhante ao realizado hoje, com todos os candidatos à $\mathrm{CNH}$, assim como todos aqueles que exerciam a profissão de motorista, submetendo-se à avaliação psicológica.

A Psicologia do Trânsito teve suas origens no Brasil nesse cenário e se manteve até a atualidade quase que exclusivamente avaliando condutores por meio de testes psicológicos. Foi apenas na década de 1980 que as críticas a esse processo começaram a aparecer de forma mais contundente. As primeiras críticas ao processo faziam alusão a dois aspectos principais, quais sejam: a escassez de estudos de validade e normatização de instrumentos psicológicos para a realidade do trânsito no país; e a falta de definição sobre o perfil do motorista brasileiro (Rozestraten, 1983).

A partir dessas críticas, foram publicados alguns poucos trabalhos referentes a mudanças na forma de atuação na área. Destacam-se as publicações de Sollero Neto (1986a; 1986b), que sugeriram modificações na legislação do trânsito, propondo especificar o chamado perfil do motorista, assim como a preparação adequada dos profissionais e a fiscalização do seu trabalho. Contudo, embora algumas publicações tenham surgido, não houve à época (nem nas décadas seguintes) mudanças em relação ao processo de avaliação, tanto no que se refere aos construtos avaliados quanto ao processo em si (Rueda, 2011). O que se observou nas décadas de 1990 e de 2000 foi a publicação de resoluções pelo CONTRAN e pelo Conselho Federal de Psicologia (CFP), que determinavam quais aspectos deveriam ser avaliados e as diretrizes para o trabalho do psicólogo na área (CONTRAN, 1998, 2008; CFP, 2000, 2009). Nesse sentido, nota-se que os documentos novamente enfatizavam a avaliação do construto da atenção.

Silva e Alchieri (2007) destacaram alguns aspectos relativos ao processo de avaliação psicológica para $\mathrm{CNH}$ no Brasil. Para os autores, a questão central, e que está relacionada ao presente estudo, é a necessidade de realizar investigações que demonstrem a eficácia da avaliação de motoristas. Os autores apresentam alguns argumentos para essa possível falta de eficácia: em primeiro lugar, a ausência de evidências de validade de critério e preditivas para os instrumentos utilizados no contexto da avaliação psicológica no trânsito; destacam, ainda, a ausência de critérios precisos para avaliar o condutor, os problemas na capacitação profissional dos psicólogos e a má qualidade do processo de avaliação.

Especificamente sobre o construto da atenção, Silva e Alchieri (2008) realizaram uma pesquisa com o objetivo de revisar os estudos empíricos brasileiros realizados entre os anos de 1949 e 2006 sobre instrumentos de avaliação da atenção e também da inteligência, utilizados no processo de avaliação psicológica para condutores. Nos resultados foi verificado que, nesse período superior a 50 anos, apenas 15 pesquisas foram publicadas e, entre elas, apenas oito se referiam ao construto da atenção. Nesse sentido, os autores realizaram importantes considerações, que também vão ao encontro da proposta deste artigo. Em primeiro lugar, mencionaram que a maioria das pesquisas teve como tema principal a validade e a padronização de instrumentos de medida, porém nenhuma delas garantiu evidências de validade de critério para o contexto do trânsito. Ainda, observaram que em apenas dois pesquisas o número amostral foi superior a 200 participantes, sendo que em todas as outras foi inferior a 140. Também sobre a questão amostral, destacaram que as tabelas de testes construídas com base nessas investigações eram provenientes de amostras de pessoas sem habilitação para dirigir, questionando se as capacidades avaliadas representam, de fato, a população de motoristas. Por fim, destacaram que a maioria dos testes de atenção apresentados pelas pesquisas já não era mais utilizada no processo de habilitação.

Mais recentemente, Rueda e Monteiro (2012) analisaram a produção científica brasileira sobre a atenção no contexto da Psicologia do Trânsito entre 2001 e 2011, nas bases de dados Scientific Electronic Library Online (SciELO) e Periódicos Eletrônicos de Psicologia (PePSIC). Em consonância com os achados de Silva e Alchieri (2008), foi identificado um número pequeno de trabalhos (apenas sete) utilizando testes de atenção. Os autores salientaram a contradição da área, uma vez que é uma das que mais congregam profissionais, mas das que menos geram publicações.

Em relação a esse último ponto, de acordo com Silva e Alchieri (2010) também é urgente a discussão sobre a necessidade de publicações na Psicologia do Trânsito, assim como a realização de estudos que busquem verificar evidências de validade preditiva para os testes e/ou construtos utilizados no contexto do trânsito. Os autores desenvolveram uma pesquisa para tentar identificar a possibilidade de prever a ocorrência de infrações de trânsito a partir dos resultados dos testes psicológicos aplicados na avaliação para obtenção da CNH. Para isso, coletaram dados de 68 condutores que exerciam atividade remunerada como motoristas. A coleta ocorreu em dois momentos: na obtenção da habilitação e na renovação, cinco anos depois. Os resultados revelaram não 
haver diferenças significativas nos escores médios dos testes (que avaliavam os construtos atenção e inteligência) entre os grupos de motoristas com e sem infração. Em relação às correlações entre os escores dos testes e os registros de infrações, os resultados também não foram significativos. Com base nos resultados, Silva e Alchieri (2010) destacaram que pontuações altas ou baixas nos diferentes instrumentos não seriam critérios satisfatórios capazes de prever se o motorista cometeria mais ou menos infrações.

Diante do exposto, e considerando que os acidentes de trânsito são um problema de saúde pública, pois matam aproximadamente 40 mil pessoas por ano apenas no Brasil, parece clara a necessidade de que instrumentos utilizados na avaliação psicológica no contexto do trânsito possuam evidências de validade, principalmente de critério. Assim sendo, este estudo teve como objetivo fornecer evidências de validade de critério (cometimento ou não de infrações, quantidade de infrações, quantidade de pontos na $\mathrm{CNH}$, gravidade das infrações) para testes que avaliam a atenção e são utilizados no contexto da avaliação psicológica pericial para motoristas. Como mencionam Nunes e Primi (2010), a evidência de validade de critério é um dos principais métodos para a verificação da aplicabilidade de um teste.

\section{Método}

\section{Participantes}

Inicialmente, participaram da pesquisa 468 sujeitos, com idade superior a 18 anos e ambos os sexos, que passaram pelo processo para obtenção da CNH no decorrer do ano de 2010, em clínicas da capital e do interior do estado do Paraná, credenciadas pelo Departamento de Trânsito do Paraná (DETRAN-PR). Posteriormente, em setembro de 2014, junto ao DETRAN-PR foram obtidas as informações referentes às variáveis analisadas no estudo (cometimento ou não de infrações, quantidade e categoria das infrações, e número de pontos na $\mathrm{CNH}$ ); com isso, a amostra foi reduzida a 300 participantes, com idade variando entre 18 e 61 anos $(M=26,75 ; D P=10,15)$, sendo $185(61,7 \%)$ do sexo masculino. Destaca-se que a exclusão de 168 participantes não foi em detrimento das variáveis estudadas, mas pela ausência de informações contidas no cadastro - mais especificamente, na coleta inicial de dados não foi informado (ou estava incorreto) o número de Cadastro de Pessoa Física (CPF).

O total de 300 indivíduos foi dividido em 2 grupos, considerando se a pessoa tinha ou não sido autuada em infrações de trânsito nesse período de quatro anos. Assim, $215(71,66 \%)$ fizeram parte do grupo que não obteve atuação de infrações segundo o DETRAN-PR. A idade dessas pessoas variou de 22 a 63 anos $(M=25,71 ; D P=9,51)$, com $117(54,4 \%)$ homens. Por sua vez, o grupo de participantes que, segundo o DETRAN-PR, obteve atuação de infrações no período foi composto por 85 pessoas $(28,34 \%)$, com idades entre 22 e 57 anos $(M=29,38 ; D P=11,24)$, sendo $80 \%(n=68)$ do sexo masculino.

\section{Materiais e instrumentos}

Informações fornecidas pelo Departamento de Trânsito do Paraná. As informações fornecidas pelo DETRAN-PR foram referentes à autuação ou não em infrações de trânsito. Nos casos em que constavam infrações, o DETRAN-PR informou a quantidade ocorrida no período, a quantidade de pontos que o indivíduo possuía e a categoria dessas violações (leves, médias, graves e gravíssimas). Tais dados foram fornecidos em planilha eletrônica *.xls. Outras informações sobre os dados fornecidos são apresentadas no tópico "Procedimentos".

Teste de Atenção Concentrada (Rueda \& Sisto, 2009). O Teste de Atenção Concentrada (TEACO-FF) fornece uma medida de atenção concentrada, que se caracteriza pela capacidade do indivíduo de selecionar apenas uma fonte de informação diante de vários estímulos distratores, em um tempo predeterminado. O resultado final do teste é obtido considerando o número de estímulos-alvo que a pessoa marcou, subtraindo os erros e as omissões que cometeu. $\mathrm{O}$ teste pode ser aplicado de forma individual ou coletiva, em um período de quatro minutos.

Quanto aos estudos psicométricos, o TEACO-FF possui evidência de validade pela comparação com a variável idade, pelo funcionamento diferencial do item (DIF), pela comparação com o TEACO, os Testes de Atenção Sustentada e Dividida (AS e AD) e o Teste Conciso de Raciocínio (TCR). Os índices de precisão variam de 0,89 a 0,99 .

Teste de Atenção Dividida e Teste de Atenção Alternada (Rueda, 2010). O Teste de Atenção Dividida (TEADI) fornece uma medida referente à atenção dividida, que se caracteriza pela capacidade de procurar dois ou mais estímulos simultaneamente em um tempo predeterminado, enquanto há a presença de vários distratores ao redor. O tempo de aplicação é de cinco minutos. Em relação às propriedades psicométricas, o TEADI apresenta evidências de validade com base na comparação com a variável idade e pela comparação com os testes TEACO-FF, AD e AS, TCR e Teste Não Verbal de Inteligência - R1. No que tange aos índices de precisão, houve uma variação entre 0,83 e 0,89 .

Por sua vez, o Teste de Atenção Alternada (TEALT) avalia a atenção alternada, que indica a capacidade de uma pessoa para focar sua atenção ora em um estímulo, ora em outro, por um período de tempo determinado, e diante de vários estímulos distratores. O tempo total para a realização do teste é de 2 minutos e 30 segundos. Nos estudos psicométricos, também foram verificadas 
evidências de validade pela comparação com a idade das pessoas, assim como pela comparação com os testes TEACO-FF, AD e AS, TCR e R1. No cálculo dos índices de precisão foi observada uma variação entre 0,81 e 0,86 .

Em ambos os testes a aplicação pode ocorrer tanto individual como coletivamente. Ainda, o resultado final deles é produto da contagem de todos os estímulos-alvo assinalados, menos a somatória dos erros e das omissões cometidos pela pessoa.

\section{Procedimentos}

Inicialmente, no ano de 2009, foi feito contato com o Setor de Psicologia do DETRAN-PR para explicar os objetivos da pesquisa. Após autorização oficial, a pesquisa foi submetida para análise e aprovação de um Comitê de Ética em Pesquisa. Em posse da aprovação, foi acordada a realização de um encontro inicial entre as responsáveis técnicas do DETRAN-PR, o autor da pesquisa e as clínicas credenciadas, para explicar os objetivos do estudo e confirmar quais clínicas se disporiam a participar voluntariamente. O objetivo do encontro foi explicar qual era a finalidade do estudo e treinar as instruções de aplicação de cada um dos testes, como forma de padronizar o procedimento e minimizar possíveis erros. Oito clínicas confirmaram a participação.

A coleta de dados, que ocorreu em 2010, durou aproximadamente três meses e cada clínica aplicou os testes em aproximadamente 60 candidatos. Os instrumentos foram aplicados após a bateria de testes já estabelecida por cada psicólogo credenciado, somente após os participantes assinarem o Termo de Consentimento Livre e Esclarecido, no qual eram informados de que a aceitação ou a recusa em participar da pesquisa não influenciaria o resultado da avaliação oficial. A taxa de adesão à pesquisa foi de aproximadamente $85 \%$. A aplicação dos testes utilizados nesta pesquisa ocorreu de forma individual, em uma única sessão, e durou aproximadamente 20 minutos.

Após a coleta, os testes foram enviados para o Setor de Psicologia do DETRAN-PR, que ficou responsável por conferir a aplicação dos testes e o preenchimento do cabeçalho das folhas de teste. Posteriormente, esse material foi enviado via Correio para correção pelo autor da pesquisa, que seguiu rigorosamente as instruções dos respectivos manuais. Além das informações do resultado dos testes, foram inseridas, em planilha eletrônica, as informações que permitiriam identificar os candidatos futuramente (número de CPF).

Como acordado no início da pesquisa, em 2009, após quatro anos, em agosto de 2014, retomou-se o contato com o Setor de Psicologia do DETRAN/PR solicitando as informações referentes ao cometimento de infrações de trânsito e, no caso disso haver ocorrido, foi solicitada a informação sobre a quantidade e a categoria delas (leve, média, grave e gravíssima), assim como o número de pontos na $\mathrm{CNH}$ do candidato. O DETRAN-PR recuperou essa informação com base no número de CPF fornecido pelo candidato no momento da avaliação psicológica (realizada em 2010). Com isso, foram obtidas informações de $65 \%$ dos candidatos (ou seja, não foram conseguidos os dados de $35 \%$ deles). O tempo do DETRAN-PR para obtenção das informações e do preenchimento de planilha eletrônica em formato ${ }^{\star}$.xls foi de aproximadamente 20 dias, sendo os dados devolvidos ao pesquisador via e-mail, para dar continuidade à pesquisa.

\section{Análise de dados}

A fim de atender aos objetivos do estudo, foram realizadas estatísticas inferenciais utilizando: o teste $t$ de Student, para comparar o desempenho nos testes de atenção em função de ter ou não cometido infrações de trânsito; o teste $d$ de Cohen, para avaliar a magnitude dessas diferenças; a análise de correlação $r$ de Pearson entre a quantidade de infrações e de pontos na $\mathrm{CNH}$ com o desempenho atencional; e a análise de variância (ANOVA), para verificar possíveis diferenças na capacidade atencional em função da classificação do tipo de infração. Além disso, inicialmente foram calculadas as estatísticas descritivas dos testes e das infrações cometidas.

\section{Resultados}

Os dados descritivos (Tabela 1) dos instrumentos TEACO-FF, TEADI e TEALT mostram que em todos os testes foi alcançada a pontuação máxima possível, assim distribuída: 1 participante no TEACO-FF (178 pontos); 2 no TEADI (180 pontos); e 7 no TEALT (128 pontos).

Além disso, comparou-se a média de pontos obtida em cada teste com a média apresentada pelos respectivos manuais. Nesse sentido, os participantes da presente pesquisa tiveram pontuações médias maiores que as apresentadas nos manuais dos testes, porém, nenhuma dessas diferenças foi estatisticamente significativa. Tal inferência foi observada por meio de um teste de comparação de médias.

Tabela 1

Estatísticas descritivas dos instrumentos: Testes de Atenção Concentrada, Dividida e Alternada

\begin{tabular}{lccc}
\hline & TEACO-FF & TEADI & TEALT \\
\hline Média & 113,67 & 127,58 & 94,14 \\
DP & 9,34 & 33,20 & 24,10 \\
Mínimo & 32,00 & 19,00 & 12,00 \\
Máximo & 178,00 & 180,00 & 128,00 \\
\hline
\end{tabular}

Nota: TEACO-FF=Teste de Atenção Concentrada; TEADI=Teste de Atenção Dividida; TEALT=Teste de Atenção Alternada; $D P=$ desvio padrão. 
Do total de participantes, 215 não haviam cometido infrações. Entre os 85 que cometeram violações, a média de pontos foi $2,73(D P=5,60)$, sendo que o máximo de infrações cometidas foi oito (apenas um indivíduo). A maior parte dos participantes $(52,3 \%)$ cometeu apenas 1 infração de trânsito. No que se refere à classificação, variaram de leves a gravíssimas.

A Tabela 2 apresenta a comparação dos testes em relação à pessoa ter ou não sido autuada por infrações de trânsito. Observa-se que, em todos os casos, embora os indivíduos que não possuíam infrações de trânsito tenham apresentado pontuações médias maiores que as daqueles que não foram autuados, nenhuma das comparações foi estatisticamente significativa.

Além disso, verifica-se que as magnitudes dessas diferenças foram muito pequenas (Cohen, 1988). Dando seguimento, foi realizada uma correlação entre o número de infrações e de pontos na CNH e o desempenho nos testes de atenção. Os dados constam na Tabela 3.

Pelos dados, pode-se perceber que as seis correlações foram de magnitude nula (Cohen, 1988; Dancey \& Reidy, 2006). Com isso, a variância comum entre o desempenho atencional e o envolvimento em infrações de trânsito parece não existir. No entanto, destaca-se que nenhum coeficiente de correlação apresentou significância estatística. É importante ressaltar que a semelhança observada nos valores do número de infrações e de pontos na $\mathrm{CNH}$ com os testes de atenção se deve ao fato de os pontos na $\mathrm{CNH}$ estarem diretamente ligados ao número de infrações.

Por fim, e para verificar se a quantidade de pontos na $\mathrm{CNH}$ que os indivíduos tinham apresentava relação com o desempenho nos testes de atenção, foram criadas três categorias. Participantes com até 4 pontos $(n=14)$ formaram o primeiro grupo; aqueles que tinham de 4 a 5 pontos $(n=51)$ constituíram o segundo grupo; e, por fim, os que tinham entre 5 e 7 pontos de média na $\mathrm{CNH}(n=20)$ integraram o terceiro grupo. Feito isso, procedeu-se à ANOVA, que revelou ausência de diferenças estatisticamente significativas entre os grupos $\{$ TEACO-FF $=[F(2,84)=1,04$,

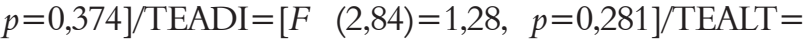
$[F(2,84)=0,57, p=0,633]\}$.

\section{Discussão}

Nas últimas décadas, a avaliação psicológica no processo para obtenção, renovação ou mudança de categoria da CNH vem sendo alvo de questionamentos (Silva \& Alchieri, 2008; Rueda, 2011; Rueda \& Monteiro, 2012). Também tem sofrido diversas alterações no que tange às normativas legais que regulamentam o processo (CONTRAN, 1998, 2008; CFP, 2000, 2009). Aliado a isso, autores como Silva e Alchieri $(2007,2010)$ ressaltam a ausência de estudos que comprovem empiricamente a existência de evidências de validade de critério e preditiva para os testes utilizados no processo.

Nesse sentido, a proposta deste estudo foi contribuir com esses tipos de evidências de validade para testes psicológicos comumente utilizados na área de trânsito. Para isso, foram selecionados três testes de atenção (TEACO-FF, TEADI e TEALT) e comparados os desempenhos de indivíduos que tinham ou não cometido infrações de trânsito.

Como resultado principal, observou-se a ausência de diferenças significativas no desempenho dos grupos. No entanto, em todos os testes o grupo de participantes sem infrações de trânsito apresentou uma média de pontos superior ao grupo de indivíduos que possuíam histórico de autuação por infrações de trânsito.

Tabela 3

Correlação entre os testes de atenção com o número de multas e de pontos na Carteira Nacional de Habilitação

\begin{tabular}{lcccc}
\hline & & TEACO-FF & TEADI & TEALT \\
\hline Número de & $r$ & 0,06 & 0,04 & 0,05 \\
infrações & $p$ & 0,367 & 0,517 & 0,458 \\
Número de & $r$ & 0,06 & 0,03 & 0,04 \\
pontos na CNH & $p$ & 0,328 & 0,642 & 0,538 \\
\hline
\end{tabular}

Nota: TEACO-FF=Teste de Atenção Concentrada; TEADI=Teste de Atenção Dividida; TEALT=Teste de Atenção Alternada; $\mathrm{CNH}=$ carteira nacional de habilitação.

Tabela 2

Comparação no desempenho nos Testes de Atenção Concentrada, Dividida e Alternada, em função de possuir ou não infrações de trânsito

\begin{tabular}{|c|c|c|c|c|c|c|}
\hline Teste & Infrações & Média & DP & $t$ & $p$ & $d$ \\
\hline \multirow{2}{*}{ TEACO-FF } & Não possui & 118,19 & 25,17 & \multirow{2}{*}{1,78} & \multirow{2}{*}{0,076} & \multirow{2}{*}{0,23} \\
\hline & Possui & 111,82 & 30,75 & & & \\
\hline \multirow{2}{*}{ TEADI } & Não possui & 131,92 & 31,62 & \multirow{2}{*}{1,29} & \multirow{2}{*}{0,201} & \multirow{2}{*}{0,19} \\
\hline & Possui & 125,82 & 33,76 & & & \\
\hline \multirow{2}{*}{ TEALT } & Não possui & 95,60 & 21,01 & \multirow{2}{*}{0,67} & \multirow{2}{*}{0,503} & \multirow{2}{*}{0,09} \\
\hline & Possui & 93,55 & 25,25 & & & \\
\hline
\end{tabular}

Nota: TEACO-FF=Teste de Atenção Concentrada; TEADI=Teste de Atenção Dividida; TEALT=Teste de Atenção Alternada; $D P=$ desvio padrão. 
Esse dado é interessante, pois, à primeira vista, pode-se pensar que, mesmo sem ter sido encontrada diferença significativa, as pessoas que posteriormente à avaliação psicológica cometeram infrações já apresentavam um nível atencional menor no momento da avaliação. Contudo, o resultado talvez possa ser olhado sob a ótica da idade desses participantes, uma vez que o grupo que cometeu infrações de trânsito apresentou uma média de idade maior $(29,38)$ do que o grupo sem infrações $(25,71)$. Nesse sentido, o resultado pode estar mais ligado à variável idade do que à variável de critério utilizada nesta pesquisa. Rueda (2010), Rueda e Sisto (2009) e Rueda e Monteiro (2012) já apontavam para a necessidade de considerar a idade das pessoas no processo de avaliação para CNH, uma vez que o resultado em testes de desempenho pode, muitas vezes, estar mais associado a questões cronológicas do que a questões do ambiente do trânsito em si.

Também é importante destacar o resultado obtido ao correlacionar o desempenho atencional com o número de infrações e de pontos da $\mathrm{CNH}$, pois a relação encontrada foi quase nula, o que indica a total ausência de associação entre essas variáveis. Esse dado se mostra relevante, pois contradiz o que o senso comum e a própria área muitas vezes preconizam como sendo relações praticamente de causa-efeito. O resultado desta pesquisa mostrou que tais relações devem ainda ser mais estudadas.

Pelo exposto, não se alcançou o objetivo proposto, que era obter evidências de validade de critério para os testes de atenção. É importante destacar que esta pesquisa utilizou o TEACO-FF, o TEADI e o TEALT, mas os resultados podem ser considerados independentemente dos testes utilizados. O que se focalizou aqui foi o desempenho atencional, e quaisquer outros instrumentos que avaliassem a atenção poderiam ter sido utilizados. Assim sendo, uma primeira sugestão para futuras pesquisas é que sejam utilizados outros instrumentos para avaliação da atenção, assim como medidas que afiram outros construtos considerados importantes para o ato de dirigir, como memória, inteligência e traços de personalidade.

Se, por um lado, neste estudo foram trabalhados apenas os resultados anteriormente destacados, por outro a maior contribuição do trabalho talvez esteja nas reflexões sobre novos aspectos e propostas a serem considerados em futuros estudos, mais do que nos aspectos verificados aqui propriamente. Nesse sentido, considerações acerca das limitações e propostas futuras serão descritas na continuação.

Ressalta-se uma limitação da pesquisa: não considerar se a pessoa recorreu ou não em caso de multa, uma vez que a infração pode ter sido cometida por outro motorista. Tal fato é considerando um grande obstáculo que não pode ser controlado, uma vez que a legislação de trânsito permite atribuir as infrações a condutores que, muitas vezes, não são os que de fato estavam dirigindo no momento da violação.

É necessário que pesquisas com números maiores de sujeitos sejam realizadas, visto que o presente estudo está longe de ser representativo da população estudada. No entanto, é um passo inicial na proposta de pesquisas dessa natureza. Esse mesmo ponto é citado por Silva e Alchieri (2010), que não encontraram diferenças significativas entre os grupos de infratores e não infratores quando compararam o desempenho em testes de atenção e inteligência de 68 motoristas. Ainda, os autores também não verificaram correlações significativas entre os escores dos testes e os pontos na CNH. Com isso, as conclusões por eles obtidas e as do presente estudo são congruentes, podendo-se afirmar que uma alta ou baixa pontuação em um determinado teste de atenção não é suficiente para definir se um motorista cometerá ou não infrações de trânsito.

É importante que outras variáveis do contexto do trânsito sejam consideradas para futuras pesquisas. Por exemplo: verificar o envolvimento em acidentes de trânsito ou não (em caso afirmativo, se houve vítimas fatais); correlacionar o resultado das provas teórica e prática com o desempenho nos instrumentos aplicados, após a aprovação na avaliação psicológica; analisar o desempenho em testes atencionais com pessoas reprovadas inicialmente e que depois obtiveram a CNH; entre outras possibilidades. Ainda, estudar a infração em si ajudaria a discutir e a refletir de forma mais aprofundada as características dos participantes. Neste estudo isso não foi possível, uma vez que as informações sobre as infrações de trânsito se limitaram a informar se eram leves, moderadas, graves ou gravíssimas, sem descrevê-las em detalhes.

Estudos como o aqui apresentado podem ser considerados um ponto de partida para se pensar a área sob uma ótica que reflita a necessidade dos construtos avaliados e a forma como eles são mensurados, assim como a importância de se realizar um processo de avaliação psicológica aprofundado, que leve em consideração não apenas o resultado apresentado em determinado(s) teste(s), mas que integre essa informação ao histórico de vida da pessoa, considerando sua realidade e aquela em que está inserido. Toda contribuição para a área é de grande interesse não apenas para a Psicologia como ciência, mas principalmente como área de atuação que tem o compromisso ético de atender eficazmente às demandas sociais da população brasileira.

\section{Agradecimentos}

O autor agradece à Marli Batagini e à psicóloga Carine Coas, do Departamento de Trânsito do Estado do Paraná, pelo auxílio de logística na coleta de dados e pelas informações fornecidas. 


\section{Referências}

Cohen, J. (1988). Statistical power analysis for the behavioral sciences. (2a edição). Hillsdale, New Jersey: Lawrence Erbaum.

Conselho Federal de Psicologia (CFP). (2000). Resolução no 012/2000. Brasília, DF: Conselho Federal de Psicologia.

Conselho Federal de Psicologia (CFP). (2009). Resolução no 007/2009. Brasília, DF: Conselho Federal de Psicologia.

Conselho Nacional de Trânsito (CONTRAN). (1998). Resolução nº 80/1998. Brasília, DF: Conselho Nacional de Trânsito.

Conselho Nacional de Trânsito (CONTRAN). (2008). Resolução no 267/2008. Brasília, DF: Conselho Nacional de Trânsito.

Dancey, C. P., \& Reidy, J. (2006). Estatística sem matemática para psicologia usando SPSS para Windows. Porto Alegre, RS: Artmed.

Nunes, C. H. S. S., \& Primi, R. (2010). Aspectos técnicos e conceituais da ficha de avaliação dos testes psicológicos. Em Conselho Federal de Psicologia (Org.). Avaliação psicológica: diretrizes na regulamentação da profissão (pp. 101-127). Brasília, DF: CFP.

Rozestraten, R. J. A. (1988). Psicologia do Trânsito: conceitos e processos básicos. São Paulo: EPU.

Rozestraten. R. J. A. (1983). Psicologia do trânsito: Sua definição e área de atuação. Psicologia \& Trânsito, 1(1), 6-19.

Rueda, F. J. M., \& Sisto, F. F. (2009). Teste de Atenção Concentrada - TEACO-FF. São Paulo: Casa do Psicólogo.

Rueda, F. J. M. (2010). Teste de Atenção Dividida (TEADI) e Teste de Atenção Alternada (TEALT). São Paulo: Casa do Psicólogo.

Rueda, F. J. M. (2011). Psicologia do trânsito ou avaliação psicológica no trânsito: faz-se distinção no Brasil? Em A. P. P., Noronha \& cols. (Orgs.) Ano da avaliação psicológica: textos geradores (pp.103-114). Brasília, DF: Conselho Federal de Psicologia.

Rueda, F. J. M., \& Monteiro, R. M. (2012). Avaliação da atenção no contexto da psicologia do trânsito: análise das publicações na área. Em E. Boruchovitch, A. A. A. Santos \& E. Nascimento (Org.). Avaliação psicológica nos contextos educativo e psicossocial (pp. 281-299). São Paulo: Casa do Psicólogo.

Silva, F. H. V. C., \& Alchieri, J. C. (2007). Avaliação psicológica da personalidade de condutores: uma revisão de literatura. Psico-USF, 12(2), 189-196.

Silva, F. H. V. C., \& Alchieri, J. C. (2008). Revisão das pesquisas brasileiras em avaliação psicológica de habilidades e inteligência de condutores. Estudos de Psicologia (Natal), 13(1), 57-64. doi: 10.1590/S1413-294X2008000100007

Silva, F. H. V. C., \& Alchieri, J. C. (2010). Validade preditiva de instrumentos psicológicos usados na avaliação psicológica de condutores. Psicologia: Teoria e Pesquisa, 26(4), 695-706. doi: 10.1590/S0102-37722010000400013

Sollero Neto, J. (1986a). Psicologia em Debate - Psicologia do Trânsito: a situação atual do uso de testes. Psicologia: Ciência e Profissão, 6(2), 27-28. doi: 10.1590/S1414-98931986000200009

Sollero Neto, J. (1986b). Psicologia em Debate - Psicologia do Trânsito: as alternativas para o psicólogo. Psicologia: Ciência e Profissão, 6(2), 24-26. doi: 10.1590/S1414-98931986000200008

Vieira, M. V. M., Pereira, A. O., \& Carvalho, A. V. (1953). O exame psicotécnico de motoristas no distrito Federal. Arquivos brasileiros de Psicotécnica, 5(4), 15-24.

\section{Sobre o autor}

Fabián Javier Marín Rueda é psicólogo. Mestre e Doutor em Psicologia. Docente da graduação e do Programa de Pós-Graduação Stricto Sensu em Psicologia da Universidade São Francisco. Bolsista Produtividade do CNPq. 